\title{
RISK ASSESSMENT IN SMALL AND MEDIUM - SIZED ENTERPRISES, SPECIFICS AND DIFFERENCES IN APPROACH
}

\author{
Mr Velimir Komadinić* \\ Institute "Lola", Belgrade, Serbia \\ Dr Dragomir Ilić \\ Institute "Lola", Belgrade, Serbia
}

The health and safety policy in Small and Medium-sized Enterprises (SMEs) demands a different approuch from that of big company. There are many differences between SMEs and their larger counterparts, and this must be taken into account when assessing risks in SMEs. The aim of this paper is analyzing he characteristics of SMEs, current economic changes and their impact on developing the health and safety policy of the company and risk assessment. Also, we will describe the importance of labor inspection service, as an important external partners in supporting small and medium-sized enterprise with risk assessment.

Key words: Small and medium-sized enterprise, Characteristics, Risk assessment, Labor inspection service

\section{INTRODUCTION}

The health and safety policy in Small and Medium-sized Enterprises (SMEs) demands a different approuch from that of big company. There are many differences between SMEs and their larger counterparts, and this must be taken into account when assessing risks in SMEs. This paper focuses on three main issues.

Firstly, the characteristics of SMEs. These characteristics influence the way SMEs manage risks in the workplace and how they carry out their risk assessment.

Secondly, the impact of current economic changes and the priorities in this specific context. Changes create new challenges for SMEs and hence new challenges for risk assessment. Risk assessment requires know-how and expirience. SMEs don't always have these competencies within their own company. Many of them have to seek external partners to help develop the health and safety policy of the company in general, and risk assessment in particular.

Thirdly, the labor inspection services should be an important external partner in helping SMEs with risk assessment, where should be guided by the principle "less sanctions but more support".

\section{SPECIFIC CARACTERISTICS OF SMES}

\section{Benefits}

The way SMEs approach the topic of risk assessment is strongly influenced by the structure and strengths of the particular SMEs, but there are some characteristics that are applicable to most of SMEs, as follows [05]:

Informal social dialogue - In most SMEs, social dialogue is conducted in a very informal way. In most of them there are no formal consultation bodies or procedures. The social dialogue in SMEs is a continuos, informal interaction between employer and employees and also among employees. Many SMEs don't have, and don't need, formal consultation bodies or procedures to identify problems or pinpoint risks. The problem and the solution are discussed at the working area (offices, shop floor, construction site, etc.)

Employer works with employees -An important advantage for most SMEs is the fact that the employer works alongside the employees. This means they can see risks in the workplace and operation first hand, and will be more likely to take measures to reduce or eliminate risk. These measures can include important inovative changes or simply small changes with great effectivness for the safety of workers and employ- 
er. With this kind of operation, risk assessment is a continuous, informal process.

Flexibility - Flexibility is the key for SMEs. Employer and employees are often required to multitask in a constantly changing envinronment. They are highly adaptable. This also means that workers have a good knowledge of how their company works, and most of workplace risks. This flexibility among staff affects the way the risk assessment is carried out.

Fast decision-making process - Another advantage of SMEs is the fast decision-making process. In biger companies when one wants to introduce changes, it's usually necessary to consult several hierarchies of menagers. In SMEs with a flat hierarchy, the employee can go directly to the right person and make a proposal. This saves both time and energy.

Family atmosphere - Employees work for the company, but are also ready to be mutually supportive and to help each other if necessary. The willingness to support colleagues creates a very special atmosphere in the company between workers and employer and between employees. This make easier for employees to correct one another, and to educate one other on risk assessment.

Easy communication - The traditional informal communication and the direct and personal relationships at all levels of an SME facilitate rapid adaptation of change and better prevention of risks. These positive elements create a sound basis for carrying out a risk assessment which is adapted to the needs of the company.

\section{Shortcomings}

On the other hand, SMEs also have some shortcomings when it comes to risk assessment. Typical problems that need to bi solved in SMEs include [05]:

Low degree of delegation - The employer is responsible for all the various tasks,from human resources management to accounting and the production process. The Health and Safety policy of the company is just one among many responsibilities. While employer remains responsible for every aspects of the company's activity, he needs to be supported by other employees in the risk assessment area.

Lack of long-term strategic vision - Another shortcoming in SMEs is that they don't have a strategic vision.Problems tend to be solved as and when they occur. They are not dealt with in advance. Because of this approach, it is difficult to teach employers how to be proactive about Health and Safety and risk assessment. In some cases, employers only take action after an accident. It is never too late to do risk assessment, but it should be done proactively.

Less formal risk assessment - Employers in SMEs tend to carry out the assessment and any preventive measures in practice, without formal documentation. Each time they have to start from scratch once more. A more formal risk assessment, using specific practical tools, would be much more productive for them in the long term. Many SMEs need improvement in this regard.

\section{CHANGES IN BUSINESS ENVIRONMENT AND PRIORITIES}

\section{Economic changes, new economic challenges}

Changes in business environment influence the work of SMEs, and therefore risk assessment. These include [05]:

- a more complex society (globalisation, structural change, rapid technological development, etc.),

- more complex business operations,

- shorter lifespan of technologies,

- customer-oriented production,

- need for company networks,

- new products and operations,

- new technologies / innovation,

- increase in outsourcing.

When we say that the changes in the business environment affect the risk assessment does not mean the scope and methodology of risk assessment but the loss of priority, because SMEs focused on solving the problems that these changes are made, and which have significant impact on the business result. Of course, this statement applies to our business environment.

Risk assessment in the workplace and work environment perceive the work organization, work processes, equipment of labor, raw materials used in technology and work processes, tools and equipment for personal protection and safety, as well as other factors that may cause risk of injuries, damage to health or illness of the employee. 
The risk assessment includes [08]:

- general information about the employer,

- a description of technology and business processes, description of tools and their grouping and description of the resources and personal protective equipment at work,

- analysis of the work organization,

- identifying and determining the risks and hazards in the workplace and working environment,

- determining the means and measures to eliminate, reduce or prevent risk,

- conclusion.

State authorities,the Ministry of Labour and Social Policy (the Commitee of Occupational Safety and Health at Work and the Labour Inspectorate)have to take these strengths and shortcomings into account when dealing and cooperating with SMEs in the field of safety and health. The real challenge for SMEs is the correct and effective application of all existing legislation. The Commitee of Occupational Safety and Health at Work and the Labour Inspectorate have to act as partners to SMEs to achieve those objectives.

\section{Legal framework and instruments available to SMEs in the risk assessment}

At the state level security issues and occupational health deals with the Ministry of Labour, Employment and Social Policy, and within it, the Committee of Occupational Safety and Health at Work - OSH Committee and the Labour Inspectorate (previously mentioned). In accordance to the Law on Safety and Health, OSH Committee performs state administration with the aim to improve and develop safety and health at work and reduce occupational injuries, occupational diseases and diseases related to work.

According to Article 60. of Law, this OSH Committee performs the following tasks [07]:

- preparation of regulations concerning occupational safety and health, as well as reviews for their implementation,

- prepares technical basis for the development of the national development program of safety and health at work and monitors its exercise,

- provides technical assistance in the areas of health and safety at work,
- preparation of methodology for conducting examinations and tests in the field ofsafety and health at work,

- explores and encourages development in the area of humanization of labor,

- organizes preparation and professional examinations to conduct safety and health (OSH person and responsible person),

- supervises the legality of legal persons and entrepreneurs, as well as responsible persons with the license and the preparation of solutions for the issuance and revocation of licenses,

- collects and analyzes data on injuries, occupational diseases and illnesses related to work and issues that affect the health of employees,

- organizes professional conferences, educates employees, employers, persons OHS, inspectors and others,

- to the application as international, (EU) legislation in the area of safety and health at work,

- encourage training and development culture occupational safety and health at work.

Inspection in the field of OHS's, according to the law on health and safety at work, is done by the ministry of labor (Labour Inspectorate) through the labor inspector. The labor inspector has the right and obligation to control the implementation of measures for safety and health at work, and in particular hygiene and working conditions, production, distribution, use and maintenance of assets, resources and equipment for personal protection and safety, dangerous substances used in the work, and to [07]:

- control of general and individual acts, records and other documents,

- take statements from responsible and interested parties,

- employers, employees, and representatives of their union gives explanations and advices in the field of OHS,

- take samples for analysis, expertise, etc..,

- order measurements performed by another professional organization when the employer itself or through a particular professional organization performs measurements in the relevant fields, and measurement results provide a basis for it, 
- report to the employer and the employee or representative of employees on the inspection and supervision of the established condition,

- The next important state institution that participates in the affairs of the OHS's is Occupational Health Service. For the performance of health at work the employer engage occupational health services, which performs the following tasks [07],

- participates in the identification and assessment of risks in the workplace and work environment when creating document on risk assessment,

- carries out preliminary and periodic medical examinations at workplaces with high risk and issue reports of medical examinations in accordance with the regulations on $\mathrm{OSH}$-in,

- provides staff training in first aid,

- evaluates and identifies specific health skills that must be met by an employee to perform certain tasks at work or at risk for handling certain work equipment,

- advises the employer in the selection and testing of new assets, hazardous materials and resources nopreme for occupational safety, the health aspect,

- advises the employer in selecting appropriate job to another medical fitness of the employee,

- participates in the analysis ardu injuries, occupational diseases and diseases related to work,

- cooperates directly with the person of health and safety at work.

Safety and health jobs at work may be performed by a person who has passed the examination in accordance with the law. The employer may designate one or more of its employees, the state exam, or to hire a legal entity that holds a license (hereinafter referred to as the person of health and safety at work). Person for safety and health at work has a key role in the performance of safety and health at work in any company, even in the SMP, and these activities are [07]:

- participation in drafting legislation on risk assessment,

- control counseling employers in the planning, selection, use and maintenance of work equipment, hazardous materials and resources iopreme for occupational safety,

- participation in equipping and regulation of the workplace in order to ensure safe and healthy working conditions,

- the organization of preventive and periodic examination of the working conditions,

- the organization of preventive and periodic testing of work equipment,

- daily monitoring and control of implementation of OSH measures,

- preparation and training in safe and healthy work,

- preparation of guidelines for safe and healthy work and control of their applications,

- monitoring related to injuries and at work and occupational diseases,

- prohibition of workplace guides and resources for the work, in case of imminent danger to life and health of employees.

The existing legal framework is comprehensive and includes a number of laws, rules, regulations and directives. Also, there are certain standards in this area. We will mention some of them:

- Law on Safety and Health at Work,

- EU Council Directive 89/391,

- EU Council Directive 92/57/EEC of compliance with the minimum requirements for health and afety in the interim and mobile construction sites,

- Law on Labour,

- Regulations on the procedure for the assessment of risks in the workplace and working environment,

- Guidelines for the risk assessment of the EU, ISBN 92-827-4278-4 out in 1996.,

- Regulation on occupational safety during construction,

- Regulation on Safety and Health at Work on temporary and mobile construction sites,

- Regulation on preventive measures for safe and healthy work in the use of work equipment,

- Regulation on the general safety at work of the hazardous effects of electricity in the facilities for work, work premises and work sites,

- Regulation on preventive measures for safe and healthy work in the workplace, 
- Regulation on preventive measures for safe and healthy work when exposed to chemical substances,

- Regulation on test equipment for the testing and working environment,

- Regulation on general measures and safety at work of noise in work areas,

- Regulation on preventive measures for manual handling of loads,

- Regulation on preliminary and periodic medical examinations of employees in the workplace with increased risk,

- Standard SRPS ISO 14001/2005 Environment Management System,

- Standard SRPS OHSAS 18001 / 2008 Occpational Health and Safety Management System.

\section{Priorities}

\section{SMEs need practical and effective instruments}

The existing legislative framework for risk assessment at state level is adequate. The focus should now be on the implementation of this legislation at regional, local and company level.

Although the risk assessment is a legal obligation, many companies did not do the risk assessment act. The state could provide financial support for companies that commit to it, either through a tax relief or through funds (eg fund from fines for violating the Law on Safety and Health at Work).

In addition, companies should not be automatically held responsible for everything that goes wrong, which very often gives a negative image of entrepreneurs and entrepreneurship.

\section{Strengthening the culture of prevention}

All parties should work towards a culture of prevention. This must be based on a partnership between all the players involved and must be accompanied by substantial efforts in information provision and training and in enhancing awareness [05]. State agencies (Department of $\mathrm{OHS}$ ), professional associations, chambers of commerce need to work on promotion of risk assessment and risk prevention, as well as to encourage the exchange of best practices between companies in the same industries and between regions.

\section{The need for a partnership}

The Health and Safety policy, the risk assessment and prevention in general have to be based on a strong partnership between all players involved. There is no need for new institutions, but rather for better networking and cooperation between the relevant actors, and between sectors at all levels. We have to bundle different forces towards strong collaboration, with only one target: a better Risk Assessment in SMEs, a better health and safety environment for employer and employees.

\section{The role of labour inspection services}

The work of inspection services should be an important external factor for small and medium enterprises. They need the support of labor inspectors to better comply with regulations, especially through education, and then, when necessary, through punitive measures. Proper and effective implementation of the legislation is very important, both from the social, and economic perspective. It is expected that the labor inspection service is a modern, contemporary and professional authority. It has to be run by highly professional staff members. The establishment of a management system for OHS ensuring that the same policy and strategy are implemented, would be particularly welcome.

\section{CONCLUSION}

Risk assessment in the workplace is a central issue for all employers. However, in our country, employers are still not aware of the importance of the topic for their workforce.Another reason for lack of consideration for this area is the existence of too many legal obligations (many of OHS regulations) which, combined with a poorly designed forms and documents you need to fill in, are not helping employers in small and medium-sized enterprises to carry out their obligations. Therefore, we urgently need a strong support to facilitate the understanding of laws and regulations by small employers, and therefore its better implementation in the workplace.

Last but not least, a strong partnership between small and medium-sized enterprises and the Labour linspection Services and OSH Committee is necessary. They should provide more help for SMEs in developing the health and safety policy of the company in general, and risk assessment in particular. They should be guided by the principle of "less sanctions but more support". When 
sanctions are applied, they should be aimed at those companies which, after having been warned, still neglect health and safety or refuse to carry out a risk assessment.This is the key message of this paper.

\section{REFERENCES}

1) D. Ilic, V. Komadinić, "Risk Assessment Act of jobs at the plant for thermal desorption of FAS in Kragujevac,"Lola Institute, Belgrade, May 2011.

2) European Agency for Safety and Health at Work, Mainstreaming OSH into business management (ISBN 978-92-9191-298-8), Luxembourg, 2010.

3) Jonathan Statham, and group,Technical assessment of means of preventing crushing risks on lifts subject to directive 95/16/EC, Report Number ME/07/07, HEALT \& SAFETY LABORATORY, August 2007.

4) Ministry of Labour, Employment and Social Policy, Law on Safety and Health at Work, Official GazetteRS No. 101/05, Belgrade, 2005.
5) Ministry of Labour, Employment and Social Policy, Regulations on the procedure for the assessment of risks in the workplace and working environment, Official GazetteRS No. 101/05, Belgrade, 2005

6) Petrović, P., Milačić, V. (2010): "National technology platform Serbia - a new formal framework for re-engineering industries of Serbia“, Journal of Applied Engineering Science (Istraživanja i projektovanja za privredu), Vol. 8, No. 3, pp. 147 - 161

7) Savić, S., Stanković, M., Anđelković, B. (2010): "Preventive Engineering - System Engineering of Risk", Journal of Applied Engineering Science (Istraživanja i projektovanja za privredu), No. 9, pp. 29-35

8) V. Komadinić, D. Ilić."Employees view of the dangers and hazards in an industrial enterprise", 36 Jupiter Conference Proceedings, Belgrade 2010., Pages 118 - 121

Paper sent to revision: 23.04.2013.

Paper ready for publication: 27.08.2013. 